\title{
Análise da alocação de custos indiretos dos serviços prestados a uma organização de planos de saúde
}

\author{
Analysis of overhead allocation of services an organization of health plans
}

\section{Claudineia Kudlawicz}

Mestre em Contabilidade pela Universidade Federal do Paraná

Professora das Faculdades Opet

Endereço: Rua Ipiranga, $n^{\circ}$ 200, Bairro Capão Raso

CEP: 81110-410 - Curitiba/PR - Brasil

E-mail: claudineia09@yahoo.com.br

Telefone: (41) 3633-1483

\section{Lauro Brito de Almeida}

Doutor em Controladoria e Contabilidade pela EAC|FEA|USP

Professor do Mestrado em Contabilidade da Universidade Federal do Paraná

Endereço: Avenida Prefeito Lothário Meissner, n॰ $632-1^{\circ}$ Andar - Campus III - Bairro Jardim Botânico

CEP: 80210-170 - Curitiba/PR - Brasil

E-mail: gbrito@uol.com.br

Telefone: (41) 3360-4404

Artigo recebido em 16/11/2012. Revisado por pares em 29/03/2013. Reformulado em 30/04/2013. Recomendado para publicação em 08/05/2013 por Sandra Rolim Ensslin (Editora Científica). Publicado em 09/08/2013. 


\title{
Resumo
}

O objetivo do estudo foi investigar a robustez das alocações dos custos indiretos dos serviços prestados (CISP) aos objetos de custos de consultas, por meio do método da taxa única de alocação, calculada com base no fator da Tabela AMB e no Custo dos Serviços Médicos Prestados por Pessoas Jurídicas (SPPJ), na empresa "Alpha". Os resultados evidenciam que os CISP, ano 2010, alocados aos objetos de custos de consultas (Clínico Geral, Ginecologia, Obstetrícia e Pediatria), com base na taxa única de alocação baseada no SPPJ apresentam correlação estatisticamente significativa em contraposição à taxa única de alocação baseada no Fator Tabela AMB.

Palavras-chave: Custos em Serviços. Custo Hospitalar. Organizações de saúde.

\begin{abstract}
The objective of this study was to investigate the robustness of the overhead costs' allocations of services (from Portuguese: custos indiretos dos serviços prestados, or CISP) to the cost objects appointments, based on the factor from Table AMB and in the cost of medical services provided by corporate entities (from Portuguese: Custo dos Serviços Médicos Prestados por Pessoas Juridicas, or SPPJ) in Alpha Company. The results demonstrated that the CISP, in 2010, allocated to cost objects appointments (Physician, Gynecology, Obstetrics and Pediatrics), and based on the single rate allocation method that followed the SPPJ, present a statistically significant correlation as opposed to the single rate allocation related to the factor from Table AMB.
\end{abstract}

Keywords: Costs in services. Hospital cost. Health organizations.

\section{Introdução}

O direito fundamental das pessoas em cuidados de saúde e o dever do estado em provê-los estão reconhecidos na Constituição Federal de 1988, em seus artigos $6^{\circ}$ e 196 (BRASIL, 1990). No entanto, há reclamações de que o Estado não cumpre o dever constitucional de atender a crescente demanda por serviços de saúde com um mínimo de qualidade. Os agentes econômicos privados perceberam nessa falha do governo uma oportunidade de negócios na área de saúde: os planos de saúde. Nesse contexto, no Brasil, o discurso das empresas privadas do setor de saúde é prestar serviços com um padrão mínimo de qualidade, em contraposição ao ofertado pelo Sistema Único de Saúde (SUS). As empresas privadas do setor de saúde, que operam esses planos de saúde, formam um mercado específico denominado de mercado de saúde suplementar. Atualmente, são clientes de planos de saúde as empresas (os beneficiários são os colaboradores) e pessoas físicas.

Em sua fase inicial, não havia padronização dos planos de saúde comercializados pelas empresas privadas do setor. Os contratos eram elaborados para atender a necessidade de cada cliente e ofertavam atendimento básico aos beneficiários (SALVALAIO; SOUZA,

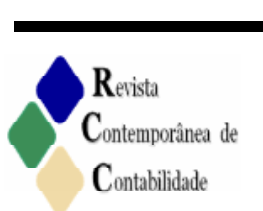

ISSN 2175-8069, UFSC, Florianópolis, v. 10, n. 20, p. 29-52, mai./ago., 2013 
2009). Após quase quarenta anos, livre de quaisquer regras, o setor foi regulamentado com a edição da Lei $n^{0}$ 9656/1998. Como parte da estruturação da regulação do setor, foi editada a Lei $n^{0}$ 9961/2000, formalizando a criação da Agência Nacional de Saúde (ANS), para, entre outras finalidades, regulamentar e fiscalizar as empresas denominadas de Operadoras de Planos de Saúde (OPS). Nesse contexto de marco regulatório, a ANS também tem poder para intervir nas empresas que estão em desacordo com as exigências impostas.

É nesse ambiente de regulação e recrudescimento da concorrência que as OPS buscam criar uma vantagem competitiva sustentável. Sobre isso, Porter $(1989$, p. 2) argumenta:

A vantagem competitiva surge fundamentalmente do valor que uma empresa consegue criar para seus compradores, e que ultrapassa o custo de fabricação pela empresa. Valor é aquilo que os compradores estão dispostos a pagar, e o superior provém da oferta de preços mais baixos do que os da concorrência, por benefícios equivalentes ou singulares que mais que compensam o preço alto.

O marco regulatório que orienta as atividades das empresas operadoras de planos de saúde impõe certas limitações na formação e gestão do preço de vendas. Nas relações das OPS com os clientes, dois tipos de contratação de planos de saúde se destacam: (i) os individuais ou familiares e (ii) os coletivos. Os planos coletivos são contratados pelas empresas, pessoas jurídicas, diferentemente do mercado individual, cujos contratantes são pessoas físicas. Essa diferenciação entre os tipos de clientes, que caracterizam mercados específicos de atuação, institui uma dinâmica diferenciada para cada um deles. O poder de negociação dos contratantes de planos individuais tende a ser inferior ao dos coletivos, os quais são conduzidos por pessoas jurídicas e de forma constante (LEAL; MATOS, 2009). Portanto, para as empresas operadoras de planos de saúde que buscam estabelecer e manter vantagem competitiva, independente do tipo de plano comercializado, é imperioso reconhecerem a importância de mensurar os custos dos serviços prestados.

A mensuração de custos no setor da saúde, de uma maneira geral, para Marques et al. (2012, p. 105) é dificultada por alguns fatores, apontados na literatura, entre eles as características próprias do setor, a assimetria de informações entre os diferentes atores e o caráter imprevisível da necessidade de cuidados de saúde do beneficiário. Um caso particular, nesse contexto, são as empresas operadoras de planos de saúde individuais e/ou coletivos. Nessas organizações, a mensuração de custos requer conhecer as singularidades dos processos operacionais, suas características e as nuanças do modelo de negócio em saúde suplementar (MEDICI; MARQUES, 1996, p. 49).

Entre as nuanças de um mercado regulado em uma atividade empresarial com forte impacto social, os preços das mensalidades, após inicialmente definidos pelas OPS, a gestão passa a ser orientada pelas regras do agente regulador. O aumento no preço das mensalidades pagas pelos clientes das OPS é definido e autorizado periodicamente pela ANS. No atual ambiente de gestão das OPS, há a necessidade de controle eficaz de custos para otimizar o resultado dessas empresas. Independente do modelo de negócio, em princípio, na equação do lucro, as variáveis passíveis de gestão pelas OPS são os custos operacionais e as despesas estruturais.

Em geral, as estruturas, os processos físicos e operacionais das organizações de natureza hospitalar consomem grande volume de recursos estruturais para prover serviços aos beneficiários dos planos de saúde, originando custos indiretos significativos. Por outro lado, considerando a participação dos médicos na prestação de serviços, a Associação Médica 
Brasileira (AMB) definiu uma tabela de valores, referências ou fatores para remuneração dos procedimentos médicos. Outros usos da tabela AMB servem para identificar o alto custo ou não de determinado procedimento e como base de alocação dos custos indiretos aos serviços prestados.

A OPS objeto deste estudo atua na modalidade de planos coletivos e aloca os custos indiretos de serviços prestados aos objetos de custos, com base no Fator Tabela AMB. No entanto, a arbitrariedade dos critérios de rateio, em geral sem bases e/ou com fundamentos econômicos de bases diferentes, provocam impactos diferenciados no custo total e unitário dos objetos de custo. Nesse contexto, este estudo é orientado pela questão de pesquisa: a alocação de custos indiretos dos serviços prestados com base no fator da Tabela AMB apresenta resultados mais robustos que a alocação com base no Custo dos Serviços Médicos Prestados por Pessoa Jurídica? Com base nessa questão, então, o propósito é investigar se a alocação de custos indiretos dos serviços prestados com base no fator da Tabela AMB apresenta resultados mais robustos que a alocação com base no Custo dos Serviços Médicos Prestados por Pessoa Jurídica em uma Unidade de Consulta Básica.

A Gestão da empresa objeto do estudo, ao optar pela tabela AMB como base para ratear os custos indiretos de serviços prestados (CISP) aos procedimentos, justifica que evita a complexa definição de rateios caracterizados, na maioria das vezes, como arbitrários. No entanto, apesar da aparente simplicidade, fica a dúvida se outras bases de alocação dos CISP apresentam resultados tecnicamente robustos. Assim, são contrapostos os resultados obtidos com a alocação de custos com base no fator da Tabela AMB com outra base: o custo dos Serviços Médicos Prestados por Pessoas Jurídicas. O método de custeio por absorção, cuja adoção é induzida por sua exigência na elaboração de relatórios externos e pelo fisco, é, em geral, utilizado para fins gerenciais. Ainda que pese a arbitrariedade dos rateios, este estudo apresenta um ângulo de análise, contribuindo, em especial, para os praticantes, com novos subsídios na escolha da base de rateio.

Além dessa introdução, este texto é estruturado em mais quatro seções. Na sequência, será apresentado o marco teórico-empírico, abordando os custos na prestação de serviços nas organizações hospitalares e alguns dos estudos relacionados ao tema. Na seção seguinte, será exposta a metodologia, relatando como o estudo, a coleta e o tratamento dos dados foram feitos. Os resultados e discussões, por sua vez, serão relatados e discutidos na seção próxima. A seguir, serão apresentadas as considerações finais e, por fim, as referências utilizadas no estudo.

\section{Marco Teórico-Empírico}

\subsection{Atividades de Prestação de Serviços no Setor de Saúde}

Pertencente ao setor terciário da economia, a prestação de serviços lidera a nova onda de expansão econômica, tendo se tornado, ao longo dos anos, uma peça fundamental no processo de crescimento global. Além dos ramos de lazer, entretenimento em geral e de estética, que cresceram significativamente nos últimos tempos, o crescimento do setor de serviços tem sido induzido pelo grande volume de terceirização das atividades empresariais.

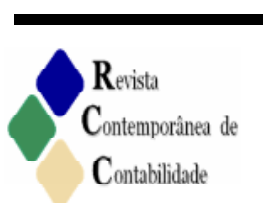

ISSN 2175-8069, UFSC, Florianópolis, v. 10, n. 20, p. 29-52, mai./ago., 2013 
No segmento de saúde, o setor de planos de saúde - que presta serviços de atendimentos à saúde - apresentou uma expansão significativa na última década. No final do ano de 2000, os planos de saúde contabilizaram 30,7 milhões de beneficiários. No final de 2011, a base de dados indicava 47,6 milhões de beneficiários (ANS, 2011) equivalente a $1 / 4$ da população brasileira. No período de 11 anos, a quantidade de beneficiários aumentou $65 \%$, com taxa de crescimento de $4,1 \%$ ao ano.

$\mathrm{O}$ setor de serviços incorpora uma grande variedade de atividades, como transporte, publicidade, computação, educação e recreação, entre outros. Para Fitzsimmons e Fitzsimmons (2005, p. 42):

Fazer a diferenciação entre um produto e um serviço é difícil, pois a compra de um produto é acompanhada de algum serviço de apoio (por exemplo, instalação) e a compra de um serviço muitas vezes inclui mercadorias (por exemplo, alimentos em um restaurante).

Para Kotlher e Bloom (1987, p. 34), o serviço, “[...] como qualquer atividade ou benefício que uma parte possa oferecer à outra, sendo essencialmente intangível e não resulte na propriedade de qualquer coisa [...] sua produção pode ou não estar vinculada a um produto físico". Contrapondo os produtos tangíveis aos intangíveis, Barzotto (2008, p. 98), argumenta que "[...] os elementos tangíveis podem ser vistos, tocados, cheirados, ouvidos ou degustados". Nas transações comerciais, constituem aspectos da oferta o próprio produto e as circunvizinhanças onde é comprado e consumido. Por outro lado, para Hoffman e Bateson (2003, p. 5) "[...] uma das formas mais fáceis de identificar um serviço é por sua natureza [...] a diferença principal entre bens e serviços é a propriedade da intangibilidade e a ausência de substância física".

Os serviços, para Hansen e Mowen (2001, p. 65), diferem dos produtos tangíveis em três dimensões importantes: (i) intangibilidade, quando não podem ser tocados; (ii) perecibilidade, quando não podem ser armazenados; e (iii) inseparabilidade, quando só podem ser realizados de forma direta. Os serviços possuem certas características intrínsecas que os distinguem da produção de bens, os quais devem ser considerados no planejamento de ações para melhoria da qualidade. Para Mattos (2008, p. 86), os serviços podem apresentar intangibilidade em maior ou menor grau, dependendo da característica do produto consumido. Por fim, a análise da qualidade e a quantificação dos serviços só são possíveis no ato do seu consumo e, por não serem estocados, serão avaliados depois de realizados. Dessa forma, Hansen e Mowen (2001, p. 65) relatam dois tipos de saída em uma empresa: produtos tangíveis e serviços.

\begin{abstract}
Os serviços, assim como os produtos, são produzidos usando materiais, mão de obra e os ativos fixos da organização, portanto, merecem o mesmo tratamento em relação à mensuração dos custos. Assim, a ausência de estoque em virtude da intangibilidade dos serviços não deve caracterizar-se como um empecilho na implementação de um sistema de custos que permita informações para a tomada de decisão.
\end{abstract}

Diante dessas particularidades, a mensuração do custo dos serviços prestados pode ser desafiadora. Além disso, a mensuração dos custos é relevante para a formação do preço de venda e gestão dos resultados. 
Nas organizações hospitalares e nas operadoras de planos de saúde, os serviços possuem todas as características discutidas: são intangíveis, não podem ser armazenados, só podem ser realizados de forma direta, não são reversíveis e contam com a variabilidade, pois dificilmente serão prestados a dois clientes de forma igual.

Por fim, considerando as características dos serviços, aliadas ao volume e à diversificação dos serviços ofertados, a mensuração de custos na área da saúde, em cada procedimento específico (objeto de custo), é uma tarefa complexa. Além disso, os custos indiretos são representativos em relação ao total dos custos incorridos na prestação de serviços, impondo dificuldades conceituais e práticas na apuração dos custos.

\subsection{Métodos de Custeio e Alocação de Custos Indiretos}

Métodos de custeio, conforme Guerreiro (2006, p. 15),

[...] representam diferentes formas de apropriação de custos aos objetos de interesse de mensuração. Decorrem da necessidade de identificar os custos de produção e de prestação de serviços de cada produto e serviço ou grupo de produtos e de serviços, de cada atividade, departamento, unidade de negócio, setor ou qualquer outra entidade econômica que consome recursos e gera resultado econômico-financeiro.

Há, conforme a literatura de custos e contabilidade gerencial (p.e., MARTINS, 2003; GUERREIRO, 2006; ZIMMERMAN, 1997, entre outros), diversos métodos de custeio, sendo os mais citados o método de custeio por absorção, o método de custeio variável e o custeio baseado em atividades. Para Zimmerman (1997, p. 303), o maior problema com o método de custeio por absorção reside na forma como os custos indiretos serão alocados ao produto. $\mathrm{O}$ autor argumenta que todos os modelos de alocação de custos apresentam fragilidades conceituais nas proposições de direcionadores de custos para custeio de produtos.

No entanto, é aceito pela legislação fiscal brasileira e para fins de publicação de relatórios externos o método de custeio por absorção. Nesse método, todos os custos associados à produção de um bem ou serviço, quer direto ou indireto, incorporam o custo do produto (MARTINS, 2003, p. 37). Para Zimmerman (1997, p. 410), o "[...] custeio por absorção proporciona que todos os custos de fabricação sejam diretamente rateados ou alocados aos vários produtos fabricados".

$\mathrm{Na}$ alocação dos custos indiretos de produção, os custos são acumulados por departamentos para posterior alocação aos produtos. Para Martins (2003, p. 65) “[...] departamento é a unidade mínima administrativa para a contabilidade de custos, representada por pessoas e máquinas (na maioria das vezes), em que se desenvolvem atividades homogêneas". Dessa maneira, entendem os proponentes do custeio por absorção que alocação dos custos acumulados nos departamentos permite distribuir de maneira mais racional os custos indiretos. Dependendo da estrutura organizacional do setor de produção, cada departamento pode abrigar um ou mais centros de custos. Para a apropriação dos custos indiretos aos produtos, todos os custos devem estar alocados aos respectivos departamentos de produção. Na sequência, os custos acumulados nos departamentos são apropriados aos produtos. Os custos diretos - bens ou serviços consumidos no processo produtivo são alocados diretamente ao produto. Nesse sentido, a 
departamentalização acompanha a estrutura organizacional, definida pelo processo físicooperacional da empresa, a fim de mensurar o custo de cada produto, independente se é um bem ou serviço.

O método de custeio baseado em atividades (ABC) é considerado como uma variante do método de custeio por absorção (GUERREIRO, 2006). Para Blocher et al. (2007, p. 132),

[...] o custeio baseado em atividades é uma abordagem que atribui custos aos produtos, serviços ou clientes, baseado no consumo de recursos causados pelas atividades. A premissa dessa abordagem é que os produtos ou os serviços de uma empresa são resultados das atividades desempenhadas por elas; elas consomem recursos que incorrem em custos. Os custos dos recursos são apropriados às atividades e as atividades são apropriadas aos objetos de custo, conforme sua utilização. $\mathrm{O}$ ABC reconhece a relação causal ou direta existente entre recursos, direcionadores, atividades e objetos de custo.

Além da alocação de custos, para Martins e Rocha (2010, p. 141), o ABC é um método de análise de custos ancorado no conceito de processos, atividades e direcionadores de custos, e seu objetivo maior é propiciar elementos informativos para a gestão de custos. $\mathrm{O}$ ABC requer o mapeamento de processos e atividades, a identificação dos fatores que determinam ou influenciam o custo das atividades e das rotas dos custos, rastreando-os aos produtos, clientes, canais de distribuição e outros. A análise por meio do ABC possibilita aos gestores a compreensão e identificação das fontes de variação dos custos e induz ações que podem reduzir a demanda pela organização de recursos (COOPER; KAPLAN, 1992).

Como proponentes do ABC, Kaplan e Norton (2001) enumeram as vantagens de seu uso para melhorar processos de desenvolvimento dos produtos, como o marketing e as vendas, a fabricação e a prestação de serviços. No entanto, Kaplan e Anderson (2004) também reconhecem que há desvantagem e que muitas empresas abandonam o ABC por não captarem a complexidade de suas operações em virtude do tempo demasiado longo e do alto custo para implantação e manutenção.

\subsection{Práticas de Custo e Custeio Meta nas Organizações do Setor de Saúde}

As organizações do setor de saúde possuem características que as diferenciam de outras instituições. Por exemplo, o foco principal de um hospital é a restauração da saúde do paciente, que tem à disposição uma gama variada de procedimentos, os quais tornam complexas as alocações de custos aos objetos de custos. Martins (2002, p. 56), por sua vez, argumenta que:

Uma atividade hospitalar é considerada como sendo um conjunto de tarefas e um processo constituído por diversas atividades relacionadas e interdependentes com a produção médica. A reunião das atividades hospitalares de apoio gerencial, de diagnóstico, de tratamento e de internação gera a cadeia de valor hospitalar ou processo hospitalar.

No contexto de atividade hospitalar, Martins (2002) explica que um conjunto de tarefas pode ser definido com os diversos tipos de consultas, exames e procedimentos 
realizados para atender as necessidades de cada paciente. Em geral, não se sabe o estado do paciente antes da primeira consulta. Pode ocorrer que o paciente, ao ser admitido, constate nos exames iniciais diversos tipos de enfermidades, físicas ou psicológicas, graves ou moderadas, cabendo à instituição hospitalar estar preparada para prestar um atendimento de qualidade e restaurar sua saúde. Para Matos (2002, p. 20), o hospital, "[...] como empresa prestadora de serviços de assistência médica, possui inúmeros itens que são produzidos no dia a dia, em razão da permanente presença de pacientes em diferentes unidades do hospital".

De acordo com a Organização Mundial de Saúde (OMS), em dados de 2010, um "[...] sistema de saúde compreende todas as organizações, instituições e recursos dedicados à realização de ações cujo objetivo primordial é melhorar a saúde". Para a OMS, a maioria dos sistemas nacionais de saúde inclui setores públicos, privados, tradicionais e informais. Cada hospital possui características próprias de sua atividade e pode atender a diferentes tipos de pacientes. No Brasil, os setores públicos atendem os participantes do Sistema Único de Saúde (SUS), assim como as empresas de saúde privada atendem os beneficiários de convênios e os que pagam pelo serviço no momento de sua utilização, classificados como particulares.

Para Cabral (2007, p. 39), o "[...] hospital é uma instituição que, mediante a função primordial de prestar assistência à saúde da população de uma determinada região, possui grande influência social, afinal, todas as pessoas são passíveis de sofrer algum tipo de moléstia em sua saúde." É fundamental, dessa forma, que as entidades hospitalares sejam eficientes e eficazes na prestação de serviços aos pacientes. A relevância dos sistemas de gestão e controle de custos, nesse contexto, contribui para a gestão dos recursos consumidos com eficiência e qualidade nos serviços prestados.

A compreensão de que o produto final do hospital não é o procedimento, mas, sim, o conjunto de procedimentos utilizados para cada paciente é fundamental para entender a relevância da utilização do controle dos custos nos departamentos. Com o crescimento das empresas e competição acirrada, a contabilidade de custos é potencialmente uma ferramenta para o processo de gestão, principalmente nas decisões relacionadas aos volumes de produção, ao mix de produção, ao controle de custos e à definição de preços de venda.

Da mesma forma que os demais tipos de organizações, as empresas que trabalham com a área da saúde competem por clientes e recursos. Para atender os clientes e beneficiários que exigem produtos e serviços com maior qualidade e preços mais baixos, a estratégia é operar com baixos custos de produção de bens e serviços sem afetar a margem de lucro desejado.

A existência de cenários envolvendo a questão dos custos nas instituições de saúde requer algumas decisões. Uma delas é a participação dos profissionais de áreas técnicas e operacionais da empresa, nem sempre possuidores de conhecimentos teóricos sobre custos. Cabe lembrar que, no setor de saúde, a participação dos profissionais técnicos nos sistemas de custos alinha-os com os processos de gestão. Dessa forma, com o aumento do uso das informações de custo por esses gestores para a tomada de decisão, é esperada melhoria na eficiência dos processos organizacionais (CHAPMAN, 2011). Ao gestor cabe, então, organizar os ativos e demais recursos disponíveis, produzir novas relações, articular processos de melhoria, criar instrumentos e desenvolver estratégias, conduzindo a instituição hospitalar a atingir seus objetivos e fins. 
Sob essa perspectiva, afirma Matos (2002, p. 21-24):

[...] o melhor gestor de custos é quem conhece profundamente as operações e não quem reúne apenas os conceitos relacionados à contabilização de custos, [...] à medida que se ignora completamente o comportamento dos custos e resultados das atividades operacionais da empresa, as condições dos dirigentes diante das decisões de investimento tornam-se extremamente inseguras.

O gestor, no desempenho de suas funções, deve ter uma visão geral de toda a empresa, do ambiente, e conhecer com detalhes as operações e o histórico da empresa. As informações de custo, nesse contexto, devem ser amplamente comunicadas aos gestores de todas as áreas para subsidiá-los nos processos de gestão e de tomada de decisão. Além disso, a existência de controles internos e sistema de custos com elevado grau de confiabilidade são imprescindíveis para uma gestão de custos eficaz no alcance das metas e objetivos de redução de custos e otimização dos lucros.

A gestão do custo não pode ocorrer dissociada das práticas e modelos de negócios dos competidores, em especial, nos ambientes marcados por alguma restrição na livre definição de preços de vendas, por características do mercado ou marco regulatório. É necessário, então, que a empresa "[...] determine o custo admissível (isto é, a "meta") para o produto ou serviço, dado um preço de mercado competitivo, de modo que a empresa possa auferir o lucro desejado: custeio-meta = preço competitivo - lucro desejado." (BLOCHER et al., 2007, p. 317).

Discorrendo sobre o custo admissível, Hansen e Mowen (2001, p. 443) argumentam:

\begin{abstract}
Um custo-alvo é a diferença entre o preço de venda necessário para se capturar uma fatia predeterminada de mercado e o lucro desejado por unidade. O preço de venda reflete as especificações ou funções do produto que são valorizadas pelo cliente (chamadas de funcionalidade do produto). Se o custo alvo for menor do que é atualmente alcançável, então a gestão deve encontrar reduções de custo que possam mover o custo real em direção ao custo-alvo [...]. (grifos do autor).
\end{abstract}

Para Martins (2003, p.223), "o custeio-alvo ou custeio meta é um processo de planejamento de lucros, preços e custos que parte do preço de venda para chegar ao custo, razão pela qual diz-se que o custo é definido de fora para dentro". Cruz e Rocha (2008), em seu estudo sobre custeio-alvo, analisaram criticamente as definições, as finalidades, os procedimentos relativos ao seu funcionamento e identificaram uma diversidade de terminologias e conceitos: p.e., custeio-alvo, custeio-meta e targeting cost. Por sua vez, Camacho (2004) argumenta que o custeio-alvo é recomendável em situações onde não há possibilidade de gestão de preços, restando como opção a concentração de esforços na gestão dos custos.

\title{
2.4 Alguns Estudos sobre Práticas de Custo e Custeio-meta
}

Raupp, Crispim e Almeida (2007) investigaram as práticas de custo em uma maternidade. Por meio da abordagem de estudo de caso, com base nos dados coletados, os achados sugerem que a principal vantagem da adoção do método de custeio por absorção pela instituição, foi atender às necessidades do gestor da maternidade. No entanto, os 
autores destacam a existência de critérios de rateio com graus de subjetividade e arbitrariedade.

Miranda et al. (2007) investigaram a utilização do custeio baseado em atividades (ABC) em hospitais universitários e compararam os achados com os das pesquisas realizadas nas maiores empresas brasileiras. Os dados foram coletados junto aos gestores dos hospitais por meio de questionários. Os achados da pesquisa sugerem que (i) os sistemas de custos possuem poucas condições de fornecer informações úteis à gestão; (ii) o ABC, apesar de bastante conhecido, é pouco utilizado e tem expectativas de uso no futuro; (iii) entre os principais motivos para a não adoção do $\mathrm{ABC}$, foram enfatizados pelos respondentes a complexidade do sistema e o não atendimento às necessidades da organização.

O estudo de Machado (2012) investigou o uso e conhecimento sobre o ABC pelas pequenas e médias empresas portuguesas. Os achados da pesquisa revelam (i) a existência de elementos que podem explicar os motivos para a não adoção do $\mathrm{ABC}$; (ii) que nenhuma das empresas investigadas utiliza o $\mathrm{ABC}$; e (iii) que a maioria não tem conhecimento sobre o assunto. Diante desses achados, o autor, listou como razões pela falta de conhecimento sobre o ABC (i) o nível hierárquico, (ii) a idade e (iii) as qualificações acadêmicas dos responsáveis pela gestão da contabilidade dessas empresas.

Chapman (2011), por sua vez, realizou um estudo exploratório em um hospital no Reino Unido, coletando dados por meio de observações, análises de documentos, entrevistas semiestruturadas e outros. O hospital investigado é considerado de alta qualidade no atendimento e com aumentos significativos nos lucros no período pesquisado. Os achados da pesquisa revelaram que a participação dos profissionais da saúde nos sistemas de custos é necessária para identificar, corrigir distorções e contribui para mensuração dos custos com alto grau de acurácia. Esse resultado sugere que os membros da organização são elementos-chave para redução das distorções ocorridas quando há desalinhamento entre os processos organizacionais e o sistema de custos.

Sobre a prática de custos em empresas operadoras de planos de saúde, há poucos estudos. A investigação de Costa, Santos e Santos (2006), sobre as práticas de custos adotadas pelas empresas operadoras de planos de saúde, relata que da amostra pesquisada ( $\mathrm{n}=13$ ), 21,7\% utilizam método de custeio por absorção, inclusive para fins de controle dos custos.

O estudo de Camacho (2004) investigou a viabilidade de aplicação do custeio-alvo - no planejamento do lucro, custos e preços - em serviços hospitalares e identificou as peculiaridades. Os objetos de sua investigação foram as cirurgias de cesarianas realizadas em pacientes beneficiárias de planos de saúde. Para coletar dados, o autor realizou entrevistas com as pacientes, com os gestores de custos do hospital e por meio de análise documental. Os achados de sua pesquisa subsidiaram a modelagem do processo de aplicação do custeio-alvo em serviços hospitalares e enumeraram aspectos não encontrados na literatura consultada.

Biazebete, Borinelli e Camacho (2009) investigaram a utilização do custeio alvo em um ambiente de método de custeio por absorção pleno em uma indústria de confecções. Os autores coletaram dados por meio de um questionário sobre o grau de importância atribuído pelos respondentes ao método de custeio por absorção pleno e o custeio-alvo. Os achados da pesquisa revelaram que (i) os princípios básicos e as etapas do processo de mensuração do custo pelo método de custeio por absorção pleno e o uso do 
custeio-alvo foram respeitados e (ii) que a gestão do planejamento do lucro por meio do custeio-alvo assegurou a margem de lucro objetivada.

\section{Metodologia}

Este estudo investiga a utilização do método da Taxa Única de Alocação dos CISP, calculada com base no Fator Tabela AMB Ponderado e Custo dos Serviços Médicos Prestados por Pessoas Jurídicas (SPPJ) na alocação dos custos indiretos de serviços prestados em uma operadora de planos de saúde. Os dados de custos são da empresa "Alpha" (nome fíctício), que comercializa e presta serviços de saúde somente para planos empresariais. A opção pela empresa "Alpha" foi feita pelo fato de um dos coautores conhecer o setor pesquisado, a empresa e o gestor de custo. Ao gestor de custo, foi explicado o interesse acadêmico e, após impostas algumas condições, como sigilo do nome da empresa, coleta dos dados e posterior utilização, a pesquisa foi autorizada. Os dados da empresa foram coletados junto à sua base de dados, por um colaborador com acesso às informações, e na presença de um dos autores, e repassadas para a realização do estudo. Os dados de custos mensais do ano de 2010 são os seguintes: (i) Custos Indiretos dos Serviços Prestados da Unidade de Serviços Consulta Básica; (ii) Custos Diretos dos Serviços de Consulta Clínico Geral, Consulta Ginecologia, Consulta Obstetrícia e Consulta Pediatria; e (iii) volume das consultas por tipo.

A Unidade de Serviços Consultas Básicas disponibiliza aos beneficiários os produtos (i) Consulta Clínica Geral, (ii) Consulta Ginecologia, (iii) Consulta Obstetrícia e (iv) Consulta Pediatria. Feita a coleta dos dados de Custos Indiretos dos Serviços Prestados (CISP), da Unidade de Serviços Consulta Básica e dos Custos Diretos dos Serviços de Consultas, o tratamento obedeceu às seguintes etapas:

1. Os CISP foram alocados aos serviços de consultas: Clínico Geral, Ginecologia, Obstetrícia e Pediatria, conforme prática vigente na empresa, por meio de uma Taxa Única de Alocação de CISP, utilizando como base o Fator Tabela AMB Ponderada.

2. Alternativamente, uma nova Taxa Única de Alocação de CISP foi calculada com base no Custo dos Serviços Médicos Prestados por Pessoas Jurídicas (SPPJ).

3. Determinadas as Taxas Únicas de Alocação de CISP, foi calculado o Custo Total de cada Serviço de Consulta. Também, para cada tipo de consulta, foram calculados dois tipos de custos totais: (i) com base na Taxa Única Fator Tabela AMB Ponderada (CT_Tabela AMB) e (ii) com base na Taxa Única SPPJ (CT_SPPJ).

4. O Coeficiente de Correlação de Pearson foi calculado para apurar a robustez do uso da base Fator Tabela AMP Ponderada e da SPPJ para cálculo da Taxa Única de Rateio, por tipo de custo total (CT_Tabela AMB e CT_SPPJ) e para cada categoria de serviço de consulta, com base nas taxas especificadas.

O coeficiente de correlação descreve o grau de associação entre as variáveis. As variáveis são correlacionadas quando a mudança em uma delas é associada com as mudanças em outra variável (HAIR JR. et al., 2005a, p. 138). Para Cunha e Coelho (2007, p. 140), o 
coeficiente de correlação varia de $-1 \mathrm{a}+1$. O sinal indica se a correlação é positiva (quando há aumento em uma variável, a outra também aumenta) ou negativa (quando uma variável aumenta, a outra reduz). Quanto mais próximo de -1 ou +1 , maior é o grau de associação entre as variáveis, e quanto mais próximo de zero, menor. Para avaliar a força de associação entre as variáveis, é sugerida a classificação (HAIR JR et al., 2005b):

Quadro 1 - Variação do coeficiente de força para associação

\begin{tabular}{|l|l|}
\hline \multicolumn{2}{|c|}{ Variação do coeficiente de força para associação } \\
\hline $\pm 0,91- \pm 1,00$ & Muito forte \\
\hline $\pm 0,71- \pm 0,90$ & Alta \\
\hline $\pm 0,41- \pm 0,70$ & Moderada \\
\hline $\pm 0,21- \pm 0,40$ & Pequena mas definida \\
\hline $\pm 0,01- \pm 0,20$ & Leve, quase imperceptível \\
\hline
\end{tabular}

Fonte: Hair Jr. et al. (2005b, p. 312).

Em resumo, quanto maior for o coeficiente de associação, mais forte será a relação. Para calcular os Coeficientes de Correlação de Pearson, foi utilizado o software XLSTAT, Versão 2010.3.06. Os coeficientes de correlação foram calculados para o Custo Total de cada tipo de serviço de consulta e as bases utilizadas para cálculo da Taxa Única de Rateio dos CISP, respectivamente, no Fator Tabela AMB e SPPJ.

\section{Resultados e Discussão}

\subsection{A empresa operadora de planos de saúde “Alpha”}

A empresa, doravante nominada de "Alpha", é uma Operadora de Planos de Saúde na modalidade de planos empresariais, e sua carteira de clientes é formada somente por empresas. As suas atividades são desenvolvidas na cidade de Curitiba/PR e região e, de acordo com os critérios da Agência Nacional de Saúde (ANS) - número de beneficiários ativos cadastrados -, é de médio porte. Nos planos empresariais, os clientes são as empresas e os funcionários, e os dependentes - beneficiários - são os consumidores finais dos serviços prestados. Os planos empresariais, objeto de contrato entre a "Alpha" e as empresas, cobrem os serviços de natureza hospitalar prestados nas dependências da "Alpha". Os estabelecimentos conveniados prestam atendimentos de pronto-socorro e emergências médicas.

A estrutura organizacional e operacional da empresa "Alpha", à semelhança das demais empresas de serviço de saúde e de acordo com a natureza desses serviços, é complexa. A sua estrutura organizacional detalha unidades que prestam distintos serviços de assistência médica. As atividades desenvolvidas pelas organizações de saúde, públicas, privadas, com fins lucrativos ou não, em geral, são complexas nos procedimentos médicos e, consequentemente, na gestão e na mensuração e dos custos, em específico.

A Unidade Integrada de Serviços Médicos (UISM) - Quadro 2 - é um Centro de Investimento, respondendo por investimentos necessários, receitas, custos e despesas. Compõem o UISM o Departamento Administrativo e as Unidades de Serviços Médicos. 
Análise da alocação de custos indiretos dos serviços prestados a uma organização de planos de saúde

Quadro 2 - Estrutura da Unidade Integrada de Serviços Médicos

\begin{tabular}{|l|c|l|}
\hline \multicolumn{1}{|c|}{ UNIDADE } & \multicolumn{2}{|c|}{ DEPARTAMENTO } \\
\hline \multirow{3}{*}{$\begin{array}{l}\text { Unidade Integrada de Serviços Médicos } \\
\text { (UISM) }\end{array}$} & Administrativo & \\
\cline { 2 - 3 } & Unidades de Serviços & Centro de Diagnóstico \\
\cline { 2 - 3 } & Médicos & Consulta Básica \\
\cline { 2 - 3 } & & Consulta Especialidade \\
\hline
\end{tabular}

Fonte: Dados da pesquisa.

Cabe lembrar que o Centro de Diagnóstico, a Consulta Básica e a Consulta Especialidade são as unidades operacionais responsáveis pela execução dos procedimentos médicos hospitalares permitidos para as Operadoras de Planos de Saúde Empresarial.

O Departamento Administrativo responde pela estrutura de serviços administrativos necessários para o desenvolvimento das atividades da UISM. Para tanto, consome recursos relativos ao pessoal, aos equipamentos (depreciação), à energia elétrica, ao telefone, ao material de expediente, entre outras despesas.

Por sua vez, o departamento Centro de Diagnósticos tem como missão a realização de exames de diagnóstico por imagem, a exemplo de mamografias, raios-X, ecografias, entre outros. Já o departamento de Consulta Especialidade realiza consultas especializadas, ou seja, todas as demais consultas, excluindo as consultas básicas, como, por exemplo, otorrinolaringologia, oftalmologia, psicologia, neurologia, psiquiatria, ortopedia, fisioterapia, e outras. No departamento de Consulta Básica são realizadas as consultas tidas como básicas, que também são as mais utilizadas pelos beneficiários. $O$ objeto de estudo é a Unidade de Serviços Médicos Consulta Básica, formada pelas unidades de serviços de consultas nas áreas de Clínico Geral, Ginecologia, Obstetrícia e Pediatria.

\subsection{Alocação dos Custos Indiretos de Serviços Prestados}

$\mathrm{Na}$ adoção do método de custeio por absorção, todos os custos de produção, diretos ou indiretos, devem ser apropriados aos objetos de custo. Em uma empresa de prestação de serviços de saúde, em geral, os elementos de custos são materiais diretos, mão de obra direta e Custos Indiretos dos Serviços Prestados. Para Warren, Reeve e Fess (2008, p. 390),

[...] materiais diretos e mão de obra direta são diretos para o produto. Entretanto, os custos indiretos [...] devem ser alocados aos produtos. [...] três diferentes abordagens de custos indiretos [...]: (i) método da taxa única de custo indireto [...], (ii) método das taxas múltiplas de custo indireto [...] dos departamentos de produção e (iii) método de custeio baseado em atividades.

No setor de saúde, Falk (2001, p. 49) argumenta que "a finalidade de um sistema aprimorado de contabilidade de custos é identificar, tão precisamente como justificável, os gastos com os pacientes/procedimentos que os causaram". Porém, além disso, para Blocher et al. (2007, p. 410), há um papel estratégico na apropriação de custos, expresso nos objetivos de: (i) determinar o custo correto do produto e do departamento, (ii) motivar os gestores responsáveis, (iii) fornecer o incentivo adequado para os gestores responsáveis e (iv) determinar corretamente os bônus a serem recebidos.

Para os propósitos do estudo, foi utilizado o método da taxa única de custo indireto de serviços prestados para alocar os custos indiretos de serviços prestados (CISP) da Unidade 
Consulta Básica aos serviços (objetos de custos), Consulta Clínico Geral, Consulta Ginecologia, Consulta Obstetrícia e Consulta Pediatria. A Figura 1 diagrama a alocação dos CISP na empresa "Alpha".

Figura 1 - Alocação dos CISP pelo Método da Taxa Única

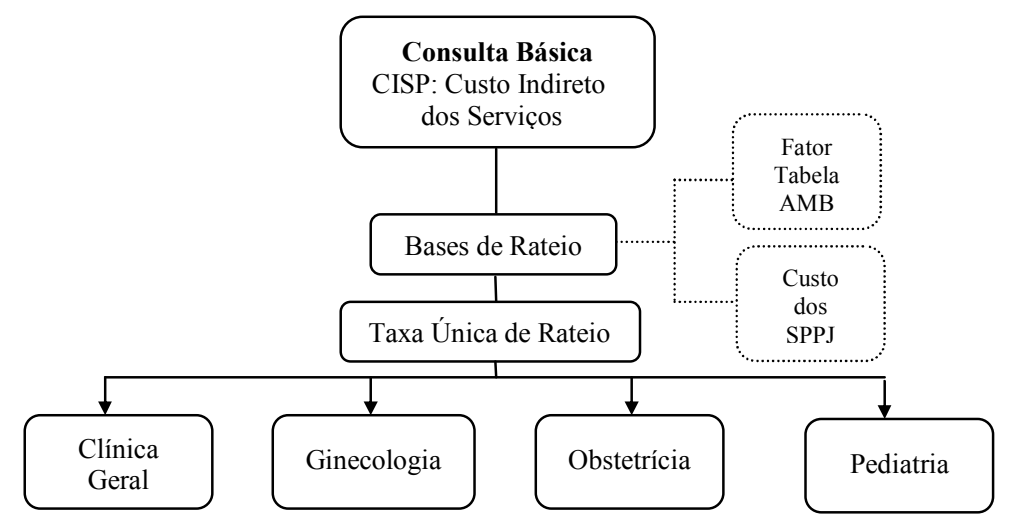

Fonte: Dados da pesquisa.

A lógica subjacente na alocação dos CISP às unidades de prestação de serviços médicos de consultas é que as unidades de consultas - Clínica Geral, Ginecologia, Obstetrícia e Pediatria -, para execução de seus serviços, consomem os serviços prestados pela unidade Consulta Básica. Os serviços de marcação de consultas, recepção, triagem e encaminhamentos dos beneficiários, serviços de computação, pequenas manutenções, materiais de expediente e outros, comunicação e vigilância são os recursos mais significativos consumidos. Em resumo, sem a estrutura fornecida pela unidade Consulta Básica, não seria possível a prestação de serviços com o mínimo de eficiência e qualidade necessária. Os CISP da Unidade Consulta Básica do ano de 2010, por natureza de despesa, estão detalhadas na Tabela 1, a seguir.

Tabela 1 - Unidade Consultas Básicas: Custos Indiretos dos Serviços Prestados (CISP)

\begin{tabular}{|c|c|c|c|c|c|c|c|c|c|c|c|c|c|}
\hline & \multicolumn{13}{|c|}{ Centro de Custo: Custos Indiretos Serviços Prestados pela Unidade de Serviço Consulta Básica | Ano: 2010 |Valores em R\$ 0,00 } \\
\hline & Jan & Fev & Mar & Abr & Mai & Jun & Jul & Ago & Set & Out & Nov & Dez & Total \\
\hline 1. Salários + ES + Benefícios & $11.848,98$ & $16.545,25$ & $13.343,69$ & $13.554,36$ & $13.607,93$ & $20.194,22$ & $13.153,86$ & $16.225,77$ & $12.010,71$ & $11.419,81$ & $10.953,55$ & $14.847,90$ & $167.706,03$ \\
\hline 2. Água & 667,33 & 348,36 & 335,94 & 329,41 & 414,59 & 366,96 & 776,33 & 767,76 & 754,28 & 728,57 & 806,95 & 860,84 & $7.157,32$ \\
\hline 3. Condução - Passagens e Taxi & - & - & . & . & - & - & 32,30 & - & - & . & 8,80 & 188,00 & 229,10 \\
\hline 4. Consertos, Substituições e Reparos & 926,50 & 98,00 & 437,00 & 586,00 & 325,00 & 17,00 & $1.711,00$ & 306,90 & $1.071,33$ & 708,00 & $1.263,00$ & 798,30 & $8.248,03$ \\
\hline 5. Conservação e manutenção & - & $\cdot$ & 661,50 & - & $\cdot$ & $\cdot$ & 848,00 & - & - & - & - & 301,36 & $1.810,86$ \\
\hline 6. CPD / Software & $3.981,20$ & $\cdot$ & $\cdot$ & $\cdot$ & $\cdot$ & $\cdot$ & $3.892,69$ & $6.651,02$ & $6.378,99$ & $5.269,41$ & $4.603,48$ & $4.841,06$ & $35.617,85$ \\
\hline 7. Depreciação / Amortização / Exaustão & $16.312,51$ & $17.676,16$ & $13.741,14$ & $15.166,94$ & $17.033,06$ & $16.394,83$ & $16.358,80$ & $16.350,23$ & $16.342,77$ & $16.338,83$ & $16.338,86$ & $16.336,16$ & $194.390,29$ \\
\hline 8. Fretes & $\cdot$ & $\cdot$ & 78,00 & $\cdot$ & $\cdot$ & $\cdot$ & $\cdot$ & $\cdot$ & $\cdot$ & $\cdot$ & $\cdot$ & $\cdot$ & 78,00 \\
\hline 9. Gás & 87,62 & $\cdot$ & $\cdot$ & $\cdot$ & $\cdot$ & $\cdot$ & $\cdot$ & 75,58 & 33,99 & 120,17 & 30,45 & 69,69 & 417,50 \\
\hline 10. Gêneros Alimenticios & 121,97 & $\cdot$ & 101,40 & 89,20 & 67,17 & 143,24 & $\cdot$ & $\cdot$ & $\cdot$ & 0,06 & 139,32 & 139,37 & 801,73 \\
\hline 11. Luz & $3.243,06$ & $1.670,03$ & $1.967,34$ & $1.583,62$ & $1.235,04$ & $1.003,99$ & $2.920,25$ & $2.757,16$ & $2.913,54$ & $2.749,01$ & $3.878,89$ & $3.161,24$ & $29.083,17$ \\
\hline 12. Material de Expediente & $2.395,88$ & $2.358,10$ & $5.148,08$ & $2.749,44$ & $2.341,03$ & $3.084,19$ & $2.432,92$ & $1.787,88$ & $2.693,58$ & $2.478,72$ & $2.249,34$ & $1.947,45$ & $31.666,61$ \\
\hline 13. Material de Higiene e Limpeza & $6.054,09$ & $6.262,56$ & $7.378,01$ & $6.716,65$ & $5.387,61$ & $5.426,84$ & $5.191,74$ & $6.339,67$ & $5.984,71$ & $6.049,61$ & $5.845,75$ & $5.804,85$ & $72.442,09$ \\
\hline 14. Outras & 20,00 & 297,39 & $1.909,95$ & 836,15 & $\cdot$ & 804,11 & 519,91 & $1.034,68$ & 769,29 & 199,77 & 352,00 & $10.686,91$ & $17.430,16$ \\
\hline 15. Outras Despesas com Comunicação & $\cdot$ & $\cdot$ & $\cdot$ & $\cdot$ & $\cdot$ & $\cdot$ & $2.760,40$ & . & $\cdot$ & $\cdot$ & $\cdot$ & $\cdot$ & $2.760,40$ \\
\hline 16. Serviços de Terceiros Pessoa Jurídica & 378,12 & $2.093,47$ & $\overline{-}$ & 74,00 & $2.800,20$ & 441,60 & 993,70 & 250,55 & 250,55 & 239,99 & 148,83 & 145,20 & $7.816,21$ \\
\hline 17. Telefone & 381,84 & 75,48 & 162,89 & 160,39 & 131,83 & 332,92 & 290,22 & 190,62 & 201,23 & 398,07 & 185,45 & 358,22 & $2.869,16$ \\
\hline 18. Vigilância & $2.415,45$ & $4.901,97$ & $2.748,54$ & $1.483,72$ & $1.852,96$ & $1.158,12$ & $1.158,12$ & $2.415,45$ & $2.415,45$ & $2.415,45$ & $2.415,45$ & $2.415,45$ & $27.796,13$ \\
\hline Total & $48.834,55$ & $52.326,77$ & $48.013,48$ & $43.329,88$ & $45.196,42$ & $49.368,02$ & $53.040,24$ & $55.153,27$ & $51.820,42$ & $49.115,47$ & $49.220,12$ & $62.902,00$ & $608.320,64$ \\
\hline
\end{tabular}

Fonte: Dados da pesquisa.

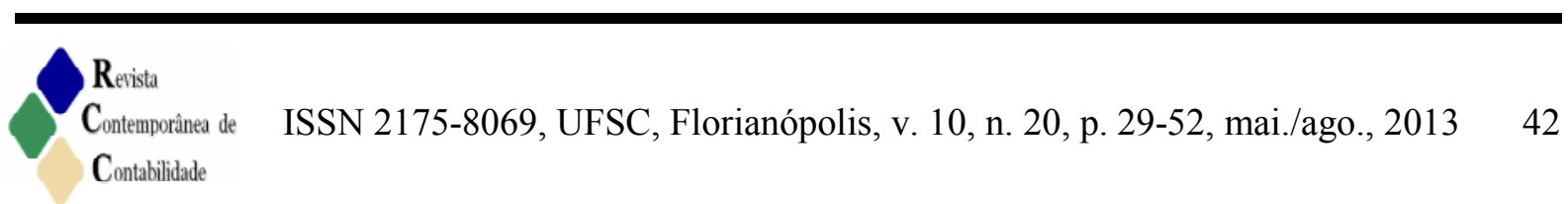


A determinação da taxa única consiste em dividir o total dos custos indiretos de serviços prestados por uma base de alocação. A base de alocação, conforme atestam Warren, Reeve e Fess (2008, p. 391) "[...] é uma medida das atividades operacionais na fábrica. Bases comuns incluiriam horas de MOD e Horas/Máquina".

Na OPS "Alpha”, serão utilizadas duas bases de alocação para determinar a taxa única de alocação dos CISP. A primeira base de alocação dos CISP é o Fator Tabela AMB Ponderada, obtida pela multiplicação do Fator Tabela AMB e quantidade de consultas realizadas, por tipo de consulta, na Unidade Consulta Básica. A segunda base de alocação é o Custo dos Serviços Médicos Prestados por Pessoas Jurídicas (SPPJ). O CISP será alocado a cada tipo de consulta prestada, de acordo com sua participação no custo total dos serviços prestados.

Com base na diagramação da Figura 1, a Taxa Única de Alocação é calculada e posteriormente utilizada para alocar os CISP às unidades de consultas nas áreas de Clínico Geral, Ginecologia, Obstetrícia e Pediatria.

\subsubsection{Alocação dos custos indiretos de serviços prestados: Consulta Clínico Geral}

A Tabela 2 detalha os valores mensais totais dos custos dos serviços prestados na Consulta Clínico Geral, pelo método da taxa única, alocados com base no Fator Tabela AMB Ponderada e no Custo dos Serviços Médicos Prestados por Pessoas Jurídicas (SPPJ).

Tabela 2 - Custo total mensal: Consulta Clínico Geral

\begin{tabular}{l|c|c|c|c}
\hline \multirow{2}{*}{ Mês } & \multicolumn{3}{|c}{ Serviço: Consulta Clínica Geral } \\
\cline { 2 - 5 } & Base Rateio (Qtde) & CT=Custo Total & Base de Rateio & CT=Custo Total \\
\cline { 2 - 5 } & Fator Tab. AMB & (1) CT AMB_CG & Br_SSPJ & (2) CT SPPJ_CG \\
\hline Jan. & 3630 & $94.417,36$ & $63.407,00$ & $92.130,05$ \\
\hline Fev. & 2930 & $92.571,65$ & $51.698,40$ & $90.722,46$ \\
\hline Mar. & 4434 & $91.392,89$ & $53.970,20$ & $92.412,56$ \\
\hline Abr. & 4089 & $91.552,80$ & $52.294,60$ & $91.374,23$ \\
\hline Mai. & 3640 & $80.375,96$ & $45.184,00$ & $79.983,01$ \\
\hline Jun. & 4152 & $90.583,55$ & $51.717,20$ & $88.876,15$ \\
\hline Jul. & 4989 & $89.478,03$ & $56.148,00$ & $88.072,73$ \\
\hline Ago. & 4862 & $95.084,68$ & $60.304,20$ & $95.432,88$ \\
\hline Set. & 3745 & $87.369,04$ & $57.868,59$ & $88.498,80$ \\
\hline Out. & 4000 & $87.195,97$ & $57.933,17$ & $88.435,21$ \\
\hline Nov. & 4071 & $93.521,74$ & $57.480,64$ & $93.417,46$ \\
\hline Dez. & 3733 & $92.162,48$ & $53.648,80$ & $92.162,48$ \\
\hline Fonte: Elaboc
\end{tabular}

Fonte: Elaboração própria.

\subsubsection{Alocação dos custos indiretos de serviços prestados: Consulta Ginecologia}

A Tabela 3 detalha os valores mensais totais dos custos dos serviços prestados Consulta Ginecologia, pelo método da taxa única, alocados com base no Fator Tabela AMB Ponderada e no Custo dos Serviços Médicos Prestados por Pessoas Jurídicas (SPPJ). 
Tabela 3 - Custo mensal total: Consulta Ginecologia

\begin{tabular}{l|c|c|c|c}
\hline \multirow{2}{*}{ Mês } & \multicolumn{4}{|c}{ Serviço: Consulta Ginecologia } \\
\cline { 2 - 5 } & Base Rateio (Qtde) & CT=Custo Total & Base de Rateio & CT=Custo Total \\
\cline { 2 - 5 } & Fator Tab. AMB & (1) CT AMB_Gineco & Br_SSPJ & (2) CT SPPJ_Gineco \\
\hline Jan. & 2709 & $88.291,58$ & $65.192,10$ & $91.935,47$ \\
\hline Fev. & 2373 & $74.838,54$ & $43.041,91$ & $73.798,16$ \\
\hline Mar. & 3690 & $66.199,08$ & $36.707,58$ & $63.953,66$ \\
\hline Abr. & 2876 & $63.090,01$ & $34.552,60$ & $62.175,72$ \\
\hline Mai. & 2957 & $64.770,15$ & $37.453,63$ & $64.735,59$ \\
\hline Jun. & 2860 & $69.695,43$ & $42.010,55$ & $70.913,16$ \\
\hline Jul. & 3534 & $67.937,54$ & $44.021,67$ & $68.604,00$ \\
\hline Ago. & 3718 & $66.008,19$ & $39.663,35$ & $63.651,49$ \\
\hline Set. & 3234 & $66.571,91$ & $42.190,22$ & $64.630,61$ \\
\hline Out. & 3531 & $66.731,21$ & $42.329,23$ & $64.712,64$ \\
\hline Nov. & 3189 & $71.427,43$ & $45.181,12$ & $71.400,32$ \\
\hline Dez. & 3248 & $79.011,45$ & $47.226,48$ & $79.011,45$ \\
\hline Fon
\end{tabular}

Fonte: Elaboração própria.

\subsubsection{Alocação dos custos indiretos de serviços prestados: Consulta Obstetrícia}

A Tabela 4 detalha os valores mensais totais dos custos dos serviços prestados em Consulta Obstetrícia, pelo método da taxa única, alocados com base no Fator Tabela AMB Ponderada e no Custo dos Serviços Médicos Prestados por Pessoas Jurídicas (SPPJ).

Tabela 4 - Custos totais mensais: Consulta Obstetrícia

\begin{tabular}{l|c|c|c|c}
\hline \multirow{2}{*}{ Mês } & \multicolumn{4}{|c}{ Serviço: Obstetrícia } \\
\cline { 2 - 5 } & Base Rateio (Qtde) & CT=Custo Total & Base de Rateio & CT=Custo Total \\
\cline { 2 - 5 } & Fator Tab. AMB & (1) CT AMB_Obst & Br_SSPJ & (2) CT SPPJ_Obst \\
\hline Jan. & 373 & $10.584,54$ & $8.190,25$ & $10.850,95$ \\
\hline Fev. & 202 & $10.411,10$ & $8.644,75$ & $12.266,68$ \\
\hline Mar. & 266 & $8.304,98$ & $6.937,00$ & $9.760,80$ \\
\hline Abr. & 291 & $10.376,43$ & $8.478,25$ & $12.046,90$ \\
\hline Mai. & 317 & $9.648,01$ & $7.853,25$ & $11.105,21$ \\
\hline Jun. & 325 & $12.225,71$ & $10.310,00$ & $14.439,16$ \\
\hline Jul. & 356 & $10.919,69$ & $9.144,00$ & $12.828,95$ \\
\hline Ago. & 354 & $11.805,67$ & $9.897,00$ & $14.069,65$ \\
\hline Set. & 318 & $11.653,05$ & $9.779,50$ & $13.572,71$ \\
\hline Out. & 390 & $11.653,05$ & $9.779,50$ & $13.572,71$ \\
\hline Nov. & 302 & $8.833,10$ & $7.148,75$ & $9.848,32$ \\
\hline Dez. & 350 & $10.679,09$ & $8.139,50$ & $10.679,09$ \\
\hline Fonte: & & & & \\
\hline
\end{tabular}

Fonte: Elaboração própria.

\subsubsection{Alocação dos custos indiretos de serviços prestados: Consulta Pediatria}

A Tabela 5 detalha os valores mensais totais dos custos dos serviços prestados em Consulta Pediatria, pelo método da taxa única, alocados com base no Fator Tabela AMB Ponderada e no Custo dos Serviços Médicos Prestados por Pessoas Jurídicas (SPPJ). 
Análise da alocação de custos indiretos dos serviços prestados a uma organização de planos de saúde

Tabela 5 - Custos total: Consulta Pediatria

\begin{tabular}{|l|c|c|c|c|}
\hline \multirow{3}{*}{ Mês } & \multicolumn{4}{|c|}{ Serviço: Pediatria } \\
\cline { 2 - 5 } & Base Rateio (Qtde) & CT=Custo Total & Base de Rateio & CT=Custo Total \\
\cline { 2 - 5 } & Fator Tab. AMB & (1) CT AMB_Ped & Br_SSPJ & (2) CT SPPJ_Ped \\
\hline Jan. & 1622 & $45.562,06$ & $26.325,00$ & $43.939,06$ \\
\hline Fev. & 1455 & $60.345,07$ & $30.674,40$ & $61.379,06$ \\
\hline Mar. & 2625 & $59.048,01$ & $29.739,80$ & $58.817,94$ \\
\hline Abr. & 2227 & $56.077,03$ & $27.123,80$ & $55.499,41$ \\
\hline Mai. & 2438 & $57.628,24$ & $28.249,60$ & $56.598,55$ \\
\hline Jun. & 2381 & $57.605,99$ & $27.671,00$ & $55.882,21$ \\
\hline Jul. & 2445 & $47.952,78$ & $26.285,40$ & $46.782,36$ \\
\hline Ago. & 2161 & $47.952,78$ & $26.285,40$ & $46.782,36$ \\
\hline Set. & 2142 & $49.238,90$ & $28.418,20$ & $48.130,78$ \\
\hline Out & 2298 & $50.771,53$ & $29.520,80$ & $50.154,65$ \\
\hline Nov. & 2218 & $54.137,63$ & $28.985,05$ & $53.253,80$ \\
\hline Dez. & 1872 & $55.255,49$ & $28.985,05$ & $55.255,49$ \\
\hline
\end{tabular}

Fonte: Elaboração própria.

\subsection{Análise dos Custos Totais de Serviços Prestados na Unidade de Consultas Básicas}

À primeira vista, os valores parecem próximos. No entanto, a alocação de custos, qualquer que seja o critério, é altamente subjetiva. Falk (2001, p. 55) orienta que a escolha da base de cálculo da taxa de alocação dos CISP deve atender aos seguintes requisitos:

1. Relação de causa e efeito: os recursos consumidos deverão ser relacionados com os custos incorridos. Quem de fato, utilizou os recursos deverá arcar com os gastos.

2. Benefícios recebidos: os gastos devem ser alocados para quem mais se beneficiou deles.

3. Equidade, justiça e capacidade de pagar: o critério adotado deverá seguir noções de aceitabilidade e ser razoável na alocação do volume de gastos para qualquer centro. Aqui, entra o princípio da responsabilidade. Os custos deverão ser alocados, inicialmente, nos centros de custos em que existe um responsável que tenha controle seu.

Os Gestores da empresa "Alpha" defendem que o Fator da Tabela AMB, peso 22, é uma "relação de causa e efeito" para alocação dos CISP aos serviços de consultas da Unidade Consulta Básica. Ao fazerem essa opção, os gestores incorrem em um erro: o Fator Tabela $\mathrm{AMB}$, peso 22, não é um recurso consumido no processo de prestação de serviços. Apenas parametriza a remuneração dos serviços médicos prestados. Custo dos Serviços Prestados Pessoa Jurídica é o recurso diretamente consumido na prestação de serviços médicos de consultas. Os CISP são consumidos no apoio à prestação de serviços médicos, no caso Consulta Básica, e, por isso, o pressuposto de "relação de causa e efeito" passa a ser base de alocação dos CISP. As consultas são diferenciadas e os Custos dos Serviços Médicos Prestados por Pessoas Jurídicas refletem não só o volume de consultas, bem como o custo diferenciado em função do tipo e da complexidade da consulta.

Diferentes métodos e bases de alocação dos CISP resultam em custos totais e médios diferentes e, por sua vez, afetam o cálculo das margens de lucro e rentabilidade por tipo de serviços prestados na unidade Consulta Básica. Assim, na sequência, estar-se-á analisando, 
por meio dos Coeficientes de Correlação de Pearson, a associação entre os Custos Totais (com os CISP rateados com base na Taxa Única Fator AMB Ponderado e Taxa Única do Custo Serviços Médicos Prestados por Pessoa Jurídica (SPPJ)) e o Fator Tabela AMB e SPPJ.

\subsubsection{Análise da alocação dos custos indiretos de serviços prestados: Consulta Clínico Geral}

O método utilizado pela Gestão da "Alpha" para alocar os CISP aos serviços de consultas na Unidade Consulta Básica é o da taxa única e utiliza como base o Fator Tabela AMB Ponderada. Todos os tipos de consultas são ponderados pelo Fator Tabela $\mathrm{AMB}=22$, em termos práticos, sem efeito algum, resultando no mesmo valor caso fosse utilizado o volume de consultas. O coeficiente de correlação de Pearson, relativo ao Custo Total AMB_CG em relação ao Fator Tabela AMB Ponderado, indica a existência de associação leve, quase imperceptível $(\mathrm{r}=0,160)$, e que não é estatisticamente significativa ( $\mathrm{p}$-valor $=$ $0,620)$.

O coeficiente de correlação de Pearson do Custo Total Serviço de Consulta Clínico Geral, considerando a alocação de custo indireto pelo método da taxa única - base de rateio o Custo dos Serviços Médicos Prestados por Pessoa Jurídica (SPPJ) -, indica a existência de associação moderada $(\mathrm{r}=0,653)$ e estatisticamente significativa ( $\mathrm{p}$-valor $=0,021)$. Os resultados da análise de correlação sugerem que há correlação entre o CT SPPJ_CG e o SPPJ, e, apesar da subjetividade da prática de rateio, a utilização da Taxa Única de Alocação de Custos com base no SPPJ é a mais adequada.

\subsubsection{Análise da alocação dos custos indiretos de serviços prestados: Consulta Ginecológica}

O método utilizado pela Gestão da "Alpha" para alocar os CISP aos serviços de consultas na Unidade Consulta Básica é o da taxa única e utiliza como base o Fator Tabela AMB Ponderada. O coeficiente de Correlação de Pearson relativo ao Custo Total AMB Ginecologia, em relação ao Fator Tabela AMB Ponderado, é negativo e moderado $(\mathrm{r}=$ $0,440)$, e, estatisticamente, não é significativo ( $\mathrm{p}$-valor $=0,152)$.

Por outro lado, o coeficiente de correlação de Pearson do Custo Total Serviço de Consulta Ginecologia, considerando a alocação de custo pelo método da taxa única, utilizando como base o Custo dos Serviços Médicos Prestados por Pessoa Jurídica (SPPJ) ( $\mathrm{r}=0,938)$, é muito forte e estatisticamente significativo ( $p$-valor $<0,0001$ ). Nesse caso, há correlação entre o CT SPPJ_Ginecologia e o SPPJ e, ainda que seja subjetiva a prática de rateio, a Taxa Única de Alocação de Custos com base no SPPJ é a mais adequada.

\subsubsection{Análise da alocação dos custos indiretos de serviços prestados: Consulta Obstetrícia}

O coeficiente de Correlação de Pearson relativo ao Custo Total AMB Obstetrícia, em relação ao Fator Tabela AMB Ponderado $(\mathrm{r}=0,446)$, é moderado e estatisticamente não significativo ( $\mathrm{p}$-valor $=0,147)$. No entanto, o coeficiente de correlação de Pearson do Custo Total Serviço de Consulta Obstetrícia, considerando a alocação de custo pelo método da taxa única, utilizando como base o Custo dos Serviços Médicos Prestados por Pessoa Jurídica (SPPJ) $(r=0,982)$, é muito forte, positivo e estatisticamente significativo ( $p$-valor $<0,0001)$. Logo, há correlação entre o CT SPPJ Obstetrícia e o SPPJ, e, apesar da subjetividade da 
prática de rateio, a utilização da Taxa Única de Alocação de Custos com base no SPPJ é a mais adequada.

\subsubsection{Análise da alocação dos custos indiretos de serviços prestados: Consulta Pediatria}

A Gestão da "Alpha" aloca os CISP aos serviços de consultas na Unidade Consulta Básica, utilizando o critério da taxa única com base no Fator Tabela AMB Ponderada. O coeficiente de correlação de Pearson, calculado referente ao Custo Total AMB Pediatria, em relação ao Fator Tabela AMB Ponderado, indica existir uma correlação leve, quase imperceptível $(r=0,098)$ e é estatisticamente não significativo ( $p$-valor $=0,761)$.

Porém, o coeficiente de correlação de Pearson do Custo Total Serviço de Consulta Pediatria $(r=0,720)$ é alto e estatisticamente significativo ( $p$-valor $=0,008)$, indicando existir correlação entre o CT SPPJ Pediatria e o SPPJ. Apesar da subjetividade da prática de rateio, a Taxa Única de Alocação de Custos com base no SPPJ é a mais adequada.

\section{Considerações Finais}

Durante o desenvolvimento desta pesquisa, observou-se os procedimentos da "Alpha" para apropriar os custos incorridos aos serviços de consultas e outros. Inicialmente, os custos indiretos de serviços prestados (CISP) são alocados às Unidades de Serviços Médicos (USM) executoras das consultas. A adoção da contabilidade de custos por departamentos, segundo o gestor de custos da "Alpha", é necessária em virtude do número de procedimentos realizados pela organização. Cada USM centraliza determinados tipos de procedimentos comuns e apropria os custos nos respectivos departamentos, o que facilita a utilização dos fatores da tabela AMB.

Os serviços médicos prestados aos beneficiários, em geral, requerem complexas interações entre os serviços hospitalares e resultam em um expressivo volume de atividade. Por isso, a adoção, pela "Alpha", do rateio com base no fator da tabela AMB, argumentam os gestores, decorre da complexidade em atribuir os custos indiretos dos serviços prestados às consultas médicas e a outros (objetos de custo) sem transitar pelas USM. Por isso, de acordo com o gestor de custos, os CISP são rateados, primeiramente, às USM, baseados em critérios de rateios fundamentados em uma relação de causa versus efeitos. Em seguida, o montante acumulado nas USM é rateado aos serviços de consultas e/ou outros, com base nos fatores de ponderação definidos na tabela da Associação Médica Brasileira, válida em âmbito nacional.

A tabela AMB define fatores (que são os pesos de ponderação na alocação dos CISP à Unidade de Serviços Médicos e desta para os procedimentos), diferenciados em virtude dos insumos que são empregados e que variam de procedimento para procedimento. Essa variação ocorre em virtude do valor do serviço médico utilizado, dos insumos e medicamentos aplicados, dos equipamentos necessários, assim como da tecnologia empregada. Procedimentos mais complexos possuem um valor de ponderação maior na tabela AMB. Na USM "Consulta Básica", o fator de ponderação é o mesmo dado que a AMB considera como procedimento realizado no mesmo nível de complexidade.

$\mathrm{Na}$ visão dos gestores da "Alpha", a utilização da tabela AMB na apropriação dos CISP, as consultas e/ou outros serviços reduzem a arbitrariedade na alocação dos custos indiretos. Os gestores justificam com o argumento - aceito e institucionalizado pela prática - 
de que na tabela $\mathrm{AMB}$ os procedimentos com maiores consumos de recursos (custos maiores) estão associados com fatores de ponderações (pesos) maiores. Dessa forma, para os gestores da "Alpha", ao ratearem os custos indiretos, tendo com base esse critério, evitam maiores distorções na alocação dos CISP aos procedimentos médicos. Além do mais, destacam como vantagem da utilização da tabela $\mathrm{AMB}$ a padronização em todas as entidades de saúde na forma de alocação dos custos aos seus serviços prestados.

Em substituição à utilização da taxa única, baseada no fator da tabela AMB, para alocar os CISP aos objetos de custos, há, na abordagem de custeio por absorção, a variante sofisticada ABC. No entanto, apesar do sucesso de mídia, a sua complexidade, entre outros motivos, tem provocado uma baixa taxa de adoção, ficando, de acordo com Kaplan e Anderson (2004) em pesquisa recente, abaixo de 50\%. No Brasil, uma pesquisa de Miranda et al. (2007) em hospitais universitários relata que o ABC é conhecido, mas muito pouco utilizado por sua complexidade e por não atender às necessidades das organizações.

No entanto, ao menos na USM Consulta Básica, é utilizado um fator para todos os serviços de consultas médicas. Dessa forma, o resultado é inócuo, pois, em essência, os CISP estão sendo rateados com base no volume de consultas. Uma alternativa foi contrapor os resultados obtidos no Fator Tabela $\mathrm{AMB}$ com os resultantes da utilização do Custo dos Serviços Médicos Prestados por Pessoas Jurídicas (SPPJ), proposto neste estudo. A análise feita, com base nos Coeficientes de Correlação de Pearson, evidenciou que a Taxa Única de Alocação de CISP, calculada com base na SPPJ, produz resultados mais robustos, pois há correlação estatisticamente significativa em todos os serviços de consultas, o que não ocorre com o Fator Tabela AMB.

Falk (2001), ao discorrer sobre a escolha e base de cálculo da taxa de rateio, recomenda que a seleção seja fundamentada no bom senso. No entanto, o bom senso pode ser uma armadilha, tal como foi para os gestores da "Alpha" quando escolheram o Fator Tabela AMB. A gestão de custos tem, entre outros, o propósito de avaliar as margens de rentabilidade das UMS e a viabilidade de lançar no mercado novos produtos. Nesse sentido, ainda que continue sendo utilizado o custeio por absorção, o planejamento do lucro poderia utilizar o custeio-alvo. Em um mercado regulado, em que a gestão de preços é definida não pelos custos, mas, sim, de acordo com índices de inflação, que podem estar dissociados dos custos e despesas da OPS, a metodologia do custeio-alvo é adequada.

Uma das limitações dos achados deste estudo é a não generalização dos resultados para a empresa "Alpha" como um todo e tampouco para outras empresas do segmento. Apesar da opção dos autores, outra limitação é utilizar alternativamente apenas a taxa única como base para rateio dos CISP. A literatura de custos e contabilidade gerencial sugere outras bases de rateio. Há também a alternativa do custeio baseado em atividades. Ainda que a opção dos autores, neste estudo, seja de somente investigar uma base de rateio como alternativa ao fator da tabela $\mathrm{AMB}$, outras abordagens não seriam exequíveis, visto que a utilização de taxas múltiplas como base de rateio e a aplicação do $\mathrm{ABC}$ dependem de um aprofundamento nos detalhes físicos e operacionais da empresa, o que não seria permitido pela mesma.

No entanto, é evidente a contribuição enquanto metodologia para subsidiar a definição de um critério mais robusto, mesmo em métodos de custeio sujeitos às arbitrariedades existentes nos rateios de custos. É desejável, também, a replicação do estudo em outras empresas do ramo, ou na mesma, considerando todas as atividades. Inclusive, nessa proposição, deve-se considerar todos os tipos de contratos de prestação de serviços médicos na modalidade pessoa jurídica, pois, como visto, potencialmente podem influenciar no custo 
indireto de serviços prestados, dependendo do tipo e características do contrato firmado. Por exemplo, um contrato em que a remuneração do profissional de saúde esteja de acordo com o volume de consultas realizadas, terá um custo variável e perfeitamente identificado com o serviço prestado e a USM. Por outro lado, um contrato com pagamento mensal para um número fixo de consultas fixas, independente de serem realizadas ou não, terá um custo fixo e, na abordagem de custeio por absorção, será rateado as USM. Por fim, desde que viável na empresa pesquisada, pode-se replicar o estudo utilizando taxas múltiplas de rateio dos CISP e de aplicação do ABC.

\section{Referências}

ASSOCIAÇÃO MÉDICA BRASILEIRA. A Instituição. São Paulo: AMB, [20--].

Disponível em:

<http://www.amb.org.br/Site/Home/QUEM\%20SOMOS/Apresenta\%C3\%A7\%C3\%A3o/>. Acesso em: 28 jul. 2010.

ANS. Agência Nacional de Saúde Suplementar. Caderno de Informação da Saúde Suplementar: beneficiários, operadoras e planos - Rio de Janeiro, dezembro/2011. Disponível em:

$<$ http//www.ans.gov.br/portal/upload/informacoesss/caderno_informaca_12_2011.pdf $>$. Acesso em: 25 jun. 2011.

BARZOTTO, L. C. O ambiente de inovação em instituição hospitalar. 2008. 154 f. Dissertação (Mestrado em Administração) - Curso de Pós-Graduação em Administração da Universidade Regional de Blumenau, Blumenau, 2008.

BIAZEBETE, C. M.; BORINELLI, M. L.; CAMACHO, R. R. Análise da aplicação do custeio alvo e do custeio pleno em indústria de confecções: um estudo de caso. Revista Contabilidade e Organizações, v. 3, n. 5, p. 44-61, jan./abr. 2009.

BLOCHER, E. J. et al. Gestão Estratégica de Custos. São Paulo: MacGraw-Hill, 2007.

BRASIL. Lei no 9.656 de 03 de junho de 1998. Diário Oficial [da] República Federativa do Brasil, Poder Executivo, Brasília, DF, 04 jun. 1998.

BRASIL. Lei no 9.961 de 28 de janeiro de 2000. Diário Oficial [da] República Federativa do Brasil, Poder Executivo, Brasília, DF, 29 jan. 2000.

BRASIL. Lei $n^{\circ} 8.080$ de 19 de setembro de 1990. Diário Oficial [da] República Federativa do Brasil, Poder Executivo, Brasília, DF, 19 set. 1990.

CABRAL, L. L. D. Qualidade percebida dos serviços hospitalares: uma avaliação utilizando o método dos fatores críticos de sucesso e a escala servqual. 2007. $129 \mathrm{f}$. Dissertação (Mestrado em Engenharia da Produção) - Curso de Pós-Graduação em Engenharia da Produção da Universidade Federal de Pernambuco, Recife, 2007. 
CAMACHO, R. R. Custeio alvo em serviços hospitalares: um enfoque sob o enfoque da gestão estratégica de custos. 2004. 168 f. Dissertação (Mestrado em Ciências Contábeis) Curso de Pós-Graduação em Controladoria e Contabilidade da Faculdade de Economia, Administração e Contabilidade da Universidade de São Paulo, São Paulo, 2004.

CHAPMAN, C.; KERN, A. Developing accurate costing systems. London: Imperial College London, 2011. Disponível em:

$<$ http://papers.ssrn.com/sol3/papers.cfm?abstract_id=1909979>. Acesso em: 28 abr. 2013.

COOPER, R.; KAPLAN, R. S. Activity-Based Systems: Measuring the costs of resource Usage. Califórnia: Accounting Horizons, 1992. Disponível em:

$<$ http://host.uniroma3.it/facolta/economia/db/materiali/insegnamenti/588_3929.pdf $>$. Acesso em: 28 abr. 2013.

COSTA, R. G.; SANTOS, N. M. B. F; SANTOS, R. F. Gestão de custos: um estudo em empresas de medicina de grupo. In: CONGRESSO BRASILEIRO DE CUSTOS. 19., 2006, Belo Horizonte. Anais... Belo Horizonte: , 2006. CD-ROM.

CRUZ, C. V. O. A.; ROCHA, W. Custeio-Alvo: reflexões sobre definições, finalidades e procedimentos. Revista Contemporânea de Contabilidade, v. 1, n. 10, p. 31-51, jul./dez. 2008 .

CUNHA, J. V. A.; COELHO, A. C. Regressão Linear Múltipla. In: CORRAR, Luiz J.; PAULO, E.; DIAS FILHO, J. M. (Coord.). Análise multivariada: para os cursos de administração, ciências contábeis e economia. São Paulo: Atlas, 2007. p.131-231.

FALK, J. A. Gestão de custos para hospitais: conceitos, metodologias e aplicações. São Paulo: Atlas, 2001.

FITZSIMMONS, J. A.; FITZSIMMONS, M. J; Administração de serviços, operações, estratégias e tecnologia da informação. Tradução de J. RITTER. Porto Alegre: Bookman, 2005.

GUERREIRO, R. Gestão do lucro. São Paulo: Atlas, 2006.

HAIR, JR., J. F. et al. Análise multivariada de dados. 5. ed. Porto Alegre: Bookman, 2005a.

HAIR, JR., J. F. Fundamentos de métodos de pesquisa em administração. Porto Alegre: Bookman, 2005b.

HANSEN, D. R.; MOWEN, M. M. Gestão de custos. São Paulo: Pioneira Thomson Learning, 2001.

HOFFMAN, D. K.; BATESON, J. E. G. Princípios de marketing de serviços: conceitos, estratégias e casos. São Paulo: Pioneira Thomson Learning, 2003. 
KAPLAN, R. S.; ANDERSON, S. R. Time-Driven Activity-Based Costing. Harvard Business Review. 2004. Disponível em:

$<$ http://classes.engr.oregonstate.edu/mime/fall2012/ie475/BT_Articles/4_TimeDrivenABC.pd f>. Acesso em 28 abr. 2013.

KAPLAN, R. S.; NORTON, D. P. Transforming the Balanced Scorecard from performance measurement to strategic management: Part II. American Accounting Association, v. 15, n. 2, p. 147-160. 2001.

KOTLER, P; BLOOM, P. Marketing para serviços profissionais. São Paulo: Atlas, 1987.

LEAL, R. M.; MATOS, J. B. B. Planos de saúde: uma análise dos custos assistenciais e seus componentes. Revista de Administração de Empresas,, v. 49, n. 4, p. 447-458, out./dez. 2009.

MACHADO, M. J. C. V. Activity Based Costing Knowledge: empirical study on small and medium-size enterprises. Revista Contemporânea de Contabilidade, v. 9, n. 18, p. 167186, jul./dez. 2012.

MARQUES, R. et al. Custos da cadeia de procedimentos no tratamento do infarto agudo do miocárdio em hospitais brasileiros de excelência e especializados. Revista da Associação Médica Brasileira, v. 1, n. 58, p. 104-111. 2012.

MARTINS, D. S. Custeio hospitalar por atividades. São Paulo: Atlas, 2002.

MARTINS, E. Contabilidade de custos. 8. ed. São Paulo: Atlas, 2003.

MARTINS, E.; ROCHA, W. Métodos de custeio comparados: custos e margens analisados sob diferentes perspectivas. São Paulo: Atlas, 2010.

MATOS, A. J. Gestão de custos hospitalares: técnicas, análise e tomada de decisão. São Paulo: STS, 2002.

MATTOS, M. A. Investigação das Práticas de Contabilidade Gerencial: Um Estudo nas Empresas Prestadoras de Serviços Contábeis. 2008. 105 f. Dissertação (Mestrado em Contabilidade) - Programa de Pós-Graduação em Contabilidade da Universidade Federal do Paraná, Curitiba, 2008.

MEDICI, A. C.; MARQUES, R. M. Sistema de custos como instrumento de eficiência e qualidade dos serviços de saúde. São Paulo: Fundap, 1996.

MIRANDA, G. J. et al. Custeio ABC no ambiente hospitalar: um estudo nos hospitais universitários e de ensino brasileiros. Revista Contabilidade e Finanças, n. 44, p. 33-43, mai./ago. 2007. 
ORGANIZAÇÃO MUNDIAL DE SAÚDE. Os sistemas de saúde. Disponível em: $<$ http://www.who.int $>$. Acesso em: 09 mar. 2010.

PORTER, M. Vantagem competitiva: criando e sustentando um desempenho superior. Rio de Janeiro: Campus, 1989.

RAUPP, F. M.; CRISPIM, C. H.; ALMEIDA, E. S. Gestão de Custos Hospitalares por Meio do Custeio por Absorção: O Caso da Maternidade Carmela Dutra. Revista de Informação Contábil, v. 2, n. 1, p. 120-133, out./dez. 2007.

SALVALAIO, D.; SOUZA, M. A. Custos na rede própria de operadora gaúcha de planos de saúde. Revista de Contabilidade e Organizações, São Paulo, v. 3, n. 5, p. 142-169, jan./abr. 2009.

WARREN, C. S.; REEVE, J. M.; FESS, P. E. Contabilidade Gerencial. 2. ed. São Paulo: Thomson Learning, 2008.

ZIMMERMAN, J. L. Accounting for decision making and control. 2. ed. Boston: McGrawHill, 1997. 